\title{
ON GENERALIZED NONLINEAR VARIATIONAL INEQUALITY PROBLEMS
}

\author{
RAM U. VERMA \\ International Publications \\ 12046 Coed Drive \\ Orlando, FL 32826, USA \\ and \\ Istituto per la Ricerca di Base \\ Division of Mathematics \\ I-86075 Monteroduni (IS), Molise, Italy
}

The following nonlinear variational inequality problem, for a nonempty closed convex subset $K$ of a real Hilbert space $H$, is considered. [This generalizes an earlier work by the author accepted for publication to the Applied Mathematics Letters.]

Find $x$ in $H, w$ in $S(x)$, and $z$ in $T(x)$ such that $f(x)$ is in $K$ and

$$
\langle f(x)-[w+f(z)], v-f(x)\rangle \geq 0
$$

for all $v$ in $K$, where $S: H \rightarrow P(H), T: H \rightarrow C(H)$ and $f: H \rightarrow H$ are relaxed Lipschitz from $H$ into the power set $P(H)$, Hausdorff-Lipschitz continuous from $H$ into a family $C(H)$ of all nonempty compact subsets of $H$, and strongly monotone on $H$, respectively. The solvability of the problem is based on the reduction of the generalized nonlinear variational inequality to an equivalent nonlinear equation and then the generation of a modified iterative algorithm

$$
f\left(x_{n+1}\right)=P_{K}\left[(1-t) f\left(x_{n}\right)+t\left(w_{n}+f\left(z_{n}\right)\right)\right]
$$

for a constant $t>0$, where the sequences $\left\{x_{n}\right\},\left\{w_{n}\right\},\left\{z_{n}\right\}$ and $\left\{f\left(x_{n}\right)\right\}$ converge (under certain hypotheses) to $x$ in $H, w$ in $S(x), z$ in $T(x)$, and $f(x)$ in $K$, respectively. Here $P_{K}: H \rightarrow K$ is the projection of $H$ onto $K$. 


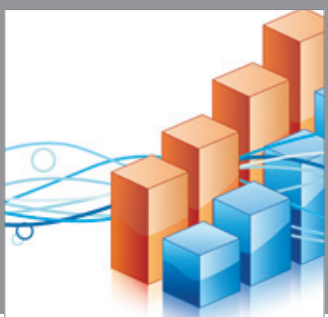

Advances in

Operations Research

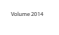

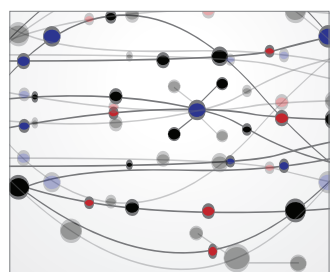

\section{The Scientific} World Journal
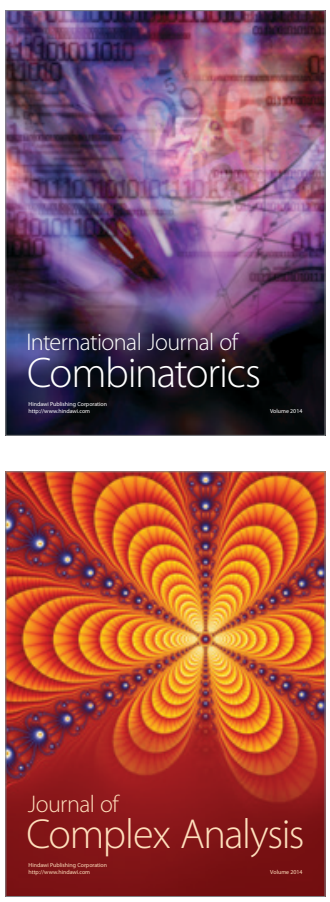

International Journal of

Mathematics and

Mathematical

Sciences
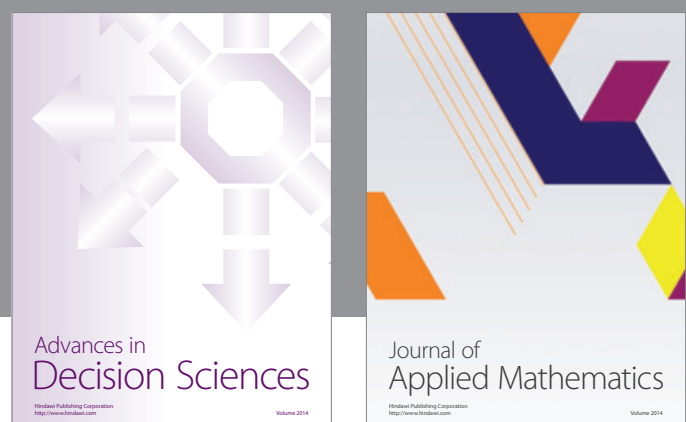

Journal of

Applied Mathematics
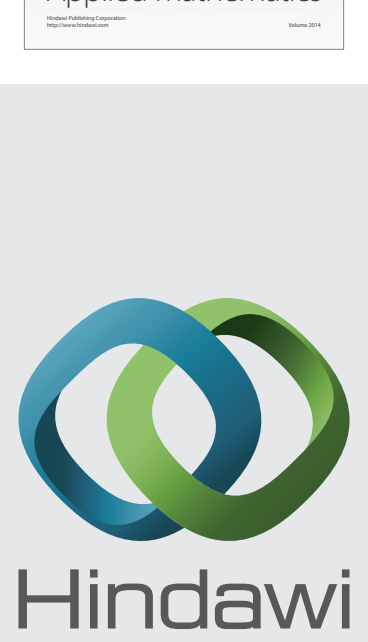

Submit your manuscripts at http://www.hindawi.com
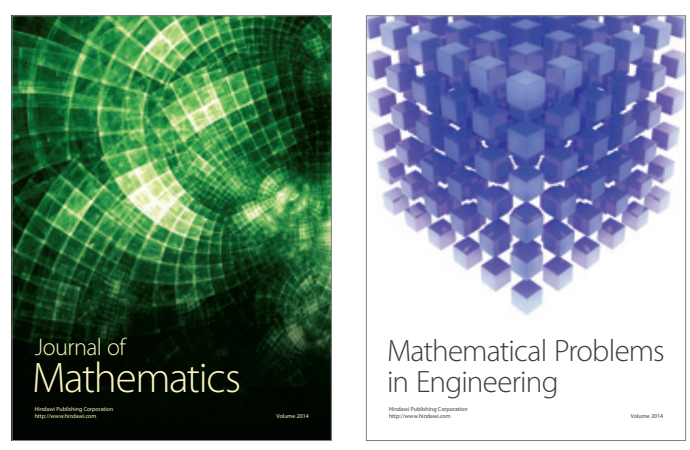

Mathematical Problems in Engineering
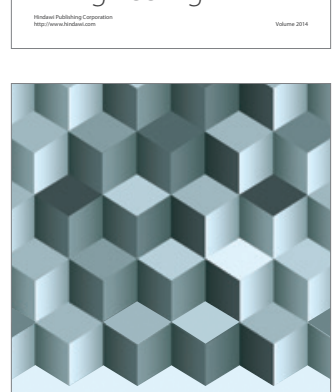

Journal of

Function Spaces
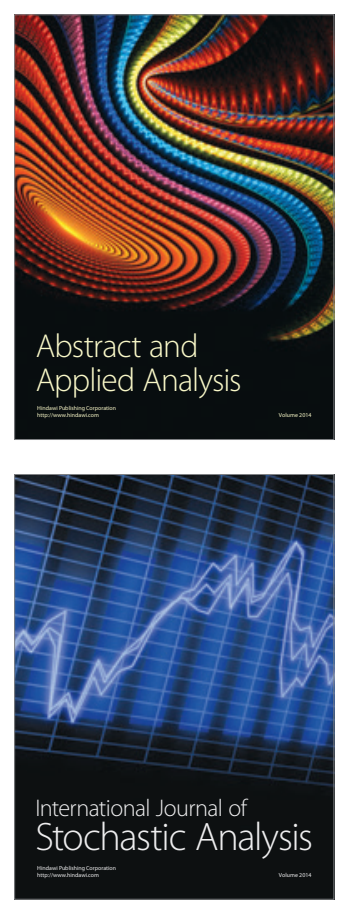

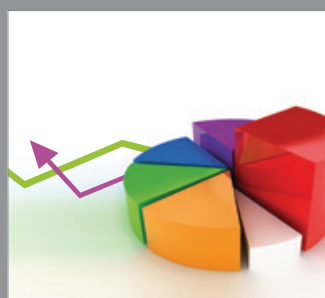

ournal of

Probability and Statistics

Promensencen
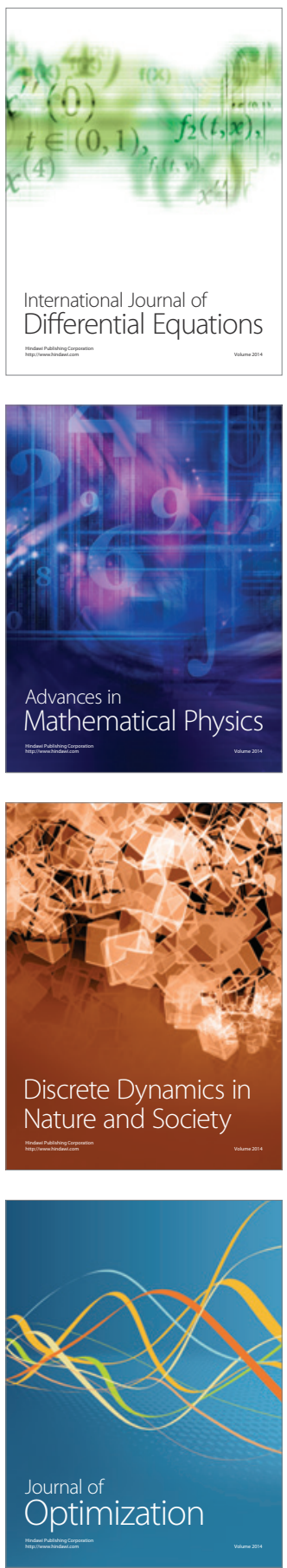